\title{
Mature Cystic Teratoma Arising in Posterior Cranial Fossa: A Rare Case Report
}

\author{
Rita Yadav ${ }^{1 *}$, Ajay Kumar Singh ${ }^{2}$, Mala Sagar ${ }^{3}$ \\ ${ }^{1}$ Assistant Professor, Department of Pathology, Career Institute of Medical Sciences, Lucknow, India \\ ${ }^{2}$ Professor, Department of Pathology, King George Medical University, Lucknow, India \\ ${ }^{3}$ Associate Professor, Department of Pathology, King George Medical University, Lucknow, India
}

DOI: $\underline{10.36348 / \mathrm{sjpm} .2020 . \mathrm{v} 05 \mathrm{i} 01.001}$

| Received: 03.01.2020 | Accepted: 14.01.2020 | Published: 23.01.2020

*Corresponding author: Rita Yadav

\section{Abstract}

Intracranial mature teratoma is a very rare neoplasm. Its location in posterior fossa of cranium is extremely rare, only few cases have been reported in English literature. Though rare, it nevertheless warrants greater emphasis than it receives in the literature. The authors report a case of mature cystic teratoma in posterior cranial fossa in a 5 month old female child. On MRI examination heterogeneously enhancing solid cystic lesion measuring $4.2 \times 4.0 \times 3.9 \mathrm{~cm}$ was noted in posterior fossa involving left cerebellar hemisphere. On histopathological examination confirm diagnosis of mature cystic teratoma was established.

Keyword: Teratoma, Intracranial, Neoplasm, solid cystic, mature.

Copyright @ 2020: This is an open-access article distributed under the terms of the Creative Commons Attribution license which permits unrestricted use, distribution, and reproduction in any medium for non-commercial use (NonCommercial, or CC-BY-NC) provided the original author and sources are credited.

\section{INTRODUCTION}

Intracranial mature teratomas represent a rare lesion accounting for $0.3-0.6 \%$ of all intracranial neoplasm and in which $2 \%-5 \%$ of all teratomas in infants. ${ }^{1}$ Intracranial teratomas are more commonly reported near the midline structure including the pineal gland and suprasellar region [2, 3]. Their location in posterior fossa is uncommon [3]. Pathologically, teratomas are classified into mature and immature type. Mature teratomas are composed of well-differentiated mature tissue represents each of the three germ cell layer of embryo that is ectoderm, mesoderm and endoderm, whereas immature teratomas contain various immature tissue, usually neuroepithelium [4]. Here the author report a case of mature cystic teratoma in posterior fossa of 3 month old female child.

\section{CASE RePOrT}

A 5 month old female child presented with unexplained excessive cry and vomiting for 20 days. On physical examination there was eyelid drooping and large head with head tilt for 20 days. On MRI examination, an ill defined heterogeneously enhancing solid cystic lesion measuring $4.2 \times 4.0 \times 3.9 \mathrm{~cm}$ displaying signal intensity alteration with non enhancing necrotic areas with mild adjacent perifocal edema in posterior fossa involving left cerebellar hemisphere, adjacent part of vermis and ipsilateral cerebellar peduncles (Figure1). The lesion was showing foci of calcification/ hemorrhage on MRI finding and having differential diagnosis of atypical teratoid \& rhabdoid tumor, ependymoma, teratoma. On basis of clinicoradiological finding craniotomy and total excision of tumor mass was done. The per operative finding was solid cystic SOL, mildly vascular, filling the posterior fossa.

Gross examination having several bits of tissue, the largest measuring $4.0 \times 3.0 \mathrm{~cm}$ in dimension. Cut surface showed grayish white solid area along with cystic cavities. Few of the bits was hard in consistency.

Histopathological examination showed the tissue derived from ectoderm, mesoderm and endoderm. The ectoderm comprising of mature glial tissue (Figure-2), nerve bundles and stratified squamous epithelium, mesodermal component having adipose tissue, blood vessels, cartilage (Figure-3) and bone trabeculae, endodermal component comprising of few glandular structure lined by columnar epithelium (Figure-3). Postoperative clinical course was uneventful and preoperative symptoms were relieved. 


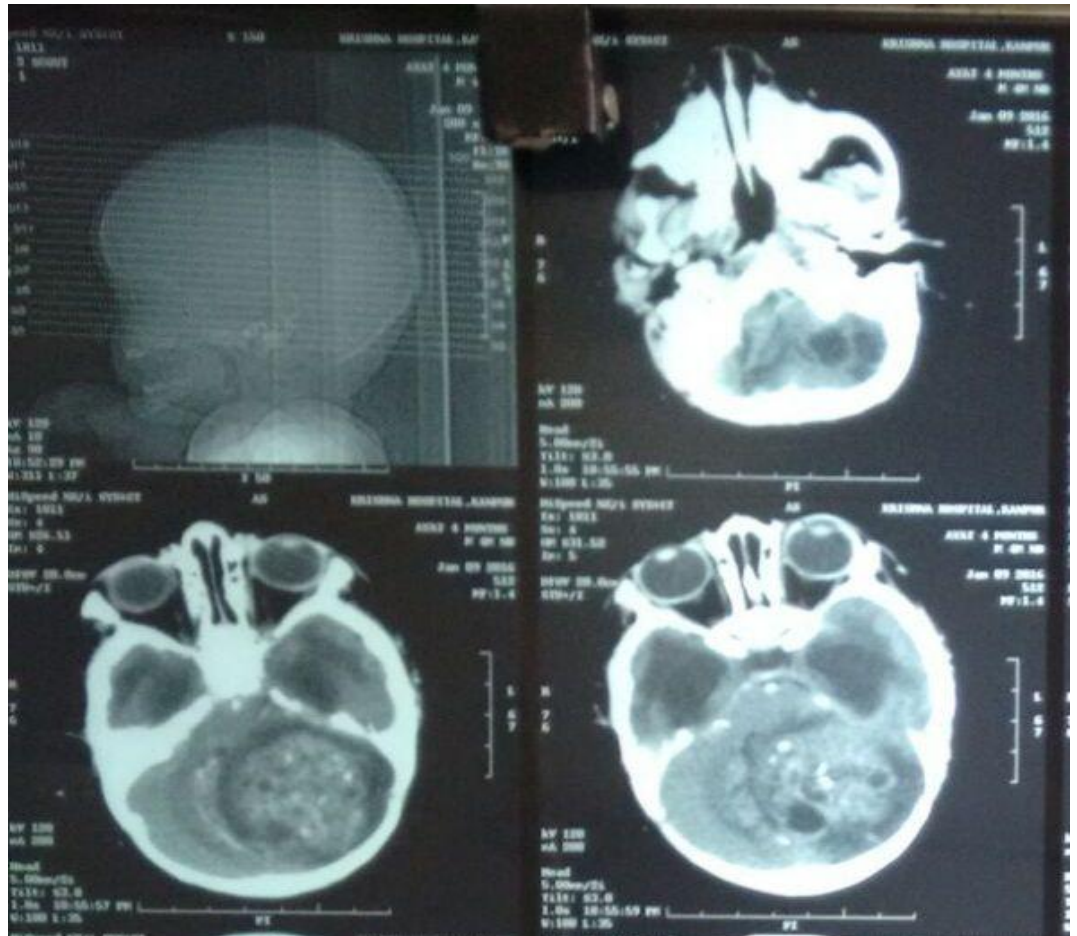

Fig-1: MRI showing an ill defined heterogeneously enhancing solid cystic lesion alteration with non enhancing necrotic areas with mild adjacent perifocal edema in posterior fossa

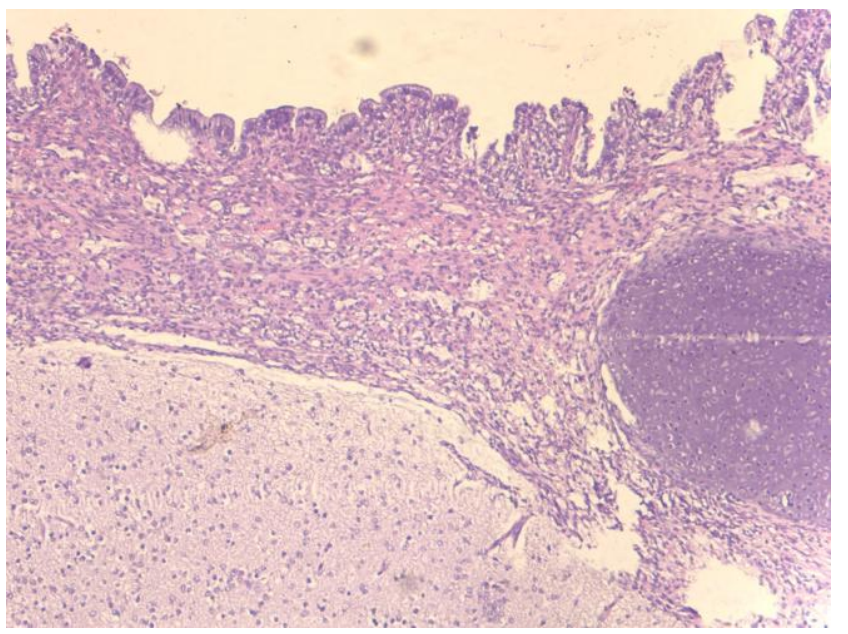

Fig-2: Microscopic examinationshowing the ectoderm comprising of mature glial tissue

\section{DISCUSSION}

Intracranial mature teratomas represents a rare neoplasm [1]. Teratomas are the most frequently occurring germ cell tumor. These tumor arise in both gonadal (ovary and testis) and extragonadal location. Gonads are most common site of origin for teratomas. Extragonadal teratomas locations are sacrococcygeal region (45-65\%), anterior mediastinum (10-12\%), retroperitoneum (3-5\%), cervical area (3-6\%), presacral area $(3-5 \%)$ and central nervous system (2-4\%) [5]. Intracranial teratomas commonly originate near the midline structure because its greater potential for misplacement of embryonal tissue. In CNS, pineal gland and suprasellar region is the most common site of origin, whereas least common site of origin in brain is



Fig-3: Microscopic examination showing cartilage, bone trabeculae, endodermal component comprising of few glandular structure lined by columnar epithelium

posterior fossa [2-5]. Posterior fossa teratomas have occurred with predominance of female whereas male predominance found in teratomas of the pineal and suprasellar region [5]. Here the author reported a case of 5 month old female child with mature cystic teratoma arising in posterior fossa region. Teratomas occurring in infancy and early childhood are generally extragonadal, whereas those presenting in older children more commonly occur in gonads [5]. Teratomas can be histologically classified into mature and immature teratoma. Mature teratomas are benign in nature and composed of well differentiated mature tissue while immature teratomas are composed of undifferentiated fetal tissue. Definitive diagnosis of teratoma was made by histopathological examination to see the tissue 
derived from 3 germ cell layers. In the classic studyon ovarian teratomas, Blackwell et al., found ectodermal derivatives in $100 \%$ of the tumors, mesodermal structures in $93 \%$, and endodermal derivatives in $71 \%$ [8]. Ectodermal components include epidermis and dermis structure like hair, sebaceous gland, sweat gland, teeth and glial tissue. Mesodermal components include fat, cartilage, bone and muscle. Endodermal components include intestinal epithelium, cystic structure lined by squamous, cuboidal or flattened epithelium and respiratory epithelium [5, 9]. The first report of a teratoma located in the midline posterior fossa was in $1912[10,11]$. To the best of our knowledge, 15 cases of mature cystic teratoma was located inposterior fossahas been reported in English literature [12]. Approximately one half of all childhood brain tumor arise in the posterior fossa [13]. Five most common type tumors that arise infratentorially are medulloblastoma, pilocytic astrocytoma, brainstem glioma, ependymoma and atypical teratoid \& rahaboid tumor. Teratomas usually arise supratentorially [10]. Aibe et al., found one infant case of teratoma located in cerebellar hemisphere without involvement of midline [14]. In our case, despite the unusual location that was posterior fossa mainly involving cerebellar hemisphere, foci of calcification and fat on imaging are highly suggestive of mature cystic teratoma elsewhere in the body. So differential diagnosis of posterior fossa pediatric tumor must include mature cystic teratomas. Mature cystic teratomas are thought to be radio resistant, and therefore the treatment of choice is total surgical resection [15].

\section{CONCLUSION}

We conclude that mature cystic teratomain unusual location and age of patient but must include in the differential diagnosis of paediatric posterior fossa tumor. Surgery is the main mode of treatment.

\section{Conflict of interest: Nil}

\section{REFERENCES}

1. Furtado, S. V., Ghosal, N., Rokade, V. B., \& Hegde, A. S. (2011). Fourth-ventricular immature teratoma. Journal of Clinical Neuroscience, 18(2), 296-298.

2. Park, K. B., Park, H. S., Lee, J. I., \& Suh, Y. L. (2007). Mature teratoma in the cerebellar hemisphere of an adult. $J$ Korean Neurosurg Soc, 41(3), 180-181.

3. Benzagmout, M., Agharbi, S., Chakour, K., \& Chaoui, M. E. (2011). Dermoid cyst of the posterior fossa. Neurosciences, 16(2):153-155.

4. Zhao, J., Wang, H., Yu, J., Zhong, Y., \& Ge, P. (2012). Cerebral falx mature teratoma with rare imaging in an adult. International journal of medical sciences, 9(4), 269-273.

5. Grosfeld, J. L., O'Neill, J. A., Coran, A. G., \& Fonkalsrud, E. W. (2006). Pediatric surgery. $6^{\text {th }}$ ed. Philadelphia: Mosby elsevier.

6. Greenhouse, A. H., \& Neubuerger, K. T. (1960). Intracranial teratomata of the newborn. Archives of neurology, 3(6), 718-724.

7. Rivero-Garvía, M., Márquez-Rivas, J., Rivas, E., \& Rueda-Torres, A. B. (2012). Extrapineal mature teratoma of the posterior fossa in a child. Open Journal of Pediatrics, 2(3), 257-259.

8. Blackwell, W. J., Dockerty, M. B., Masson, J. C., \& Mussey, R. D. (1946). Dermoid cysts of the ovary: their clinical and pathologic significance. American journal of obstetrics and gynecology, 51(2), 151-172.

9. Zavanone, M., Alimehmeti, R., Campanella, R., \& Rampini, P. (2002). Cerebellar mature teratoma in adulthood/Comments. Journal of neurosurgical sciences, 46(1), 35-38.

10. Algahtani, H. A., Al-Rabia, M. W., Al-Maghrabi, H. Q., \& Kutub, H. Y. (2013). Posterior fossa teratoma. Neurosciences, 18(4), 371-374.

11. Kischensky, D. P., \& von Tiesenhausen, M. M. (1912). Teratom des Kleinhirnsund eine Geschwulstaus Nervengewebe im Proc falciformismajor im selben Falle. Zentralbl Allg Pathol, 23:358.

12. Coulibaly, O., El Kacemi, I., Fatemi, N., Gana, R., Saïdi, A., Maaqili, R., ... \& Bellakhdar, F. (2012). Mature posterior fossa teratoma mimicking infratentorial meningioma: a case report. Neurochirurgie, 58(1), 40-43.

13. Packer, R. J. (1999). Brain Tumors in Children. Arch Neurol, 56: 421-425.

14. Aibe, M., Hirano, T., \& Takeshita, I. (2001). Teratoma in the cerebellar hemisphericof an infant. No To Hattatsu, 33:45-48.

15. Kong, D. S., Nam, D. H., Lee, J. I., Park, K., Kim, J. H., \& Shin, H. J. (2009). Intracranial growing teratoma syndrome mimicking tumor relapse: a diagnostic dilemma. Journal of Neurosurgery: Pediatrics, 3(5), 392-396. 